\title{
THERE'S AN APP FOR THAT, BUT IS THERE A MARKET FOR THAT APP? AN EXPLORATION OF THE APP MARKET AS AN AVENUE FOR ENTREPRENEURSHIP
}

\author{
George A. Kirk, Southern University, Baton Rouge, george_kirk@subr.edu
}

\begin{abstract}
Increasingly, students and recent graduates are pursuing entrepreneurial ventures as an alternative to employment. Many of these hopeful entrepreneurs are looking at the development of Smartphone applications or apps as an entrepreneurial vehicle. Popular press reports of market size and growth rates in the app market further fuel the attractiveness and desire to develop apps. While the market is attractive, there are many business factors which must be taken into consideration when considering app development as an avenue for entrepreneurship.
\end{abstract}

Keywords: Smartphone Apps, Entrepreneurship, Attractiveness, Success Factors.

\section{INTRODUCTION}

Current economic conditions and the job market have many recent college graduates considering entrepreneurship as a career choice. One seemingly attractive avenue for entrepreneurship is the smartphone applications market. Popular press frequently reports the market size and the projected growth rates of this market and the numbers are large and attractive. Success stories often make it appear that all one need do is register on one or more app developer sites do a little programing and voila. Unfortunately it is not quite that simple. The failure rate for new technology ventures is higher than the overall failure rate of new ventures [16].

The internet is replete with lists on the app development process, including videos. Table 1 [11] presents an example of the guidance that is available on the internet to iPhone add developers.

Table 1

Steps to Become an iPhone App Developer [11]

\begin{tabular}{|ll|}
\hline 1. & Buy an Apple Mac \\
\hline 2. & Download iPhone SDK \\
\hline 3. & Learn Objective C \\
\hline 4. & Understand iPhone architecture \\
\hline 5. & Sign up with Apple as an official iPhone application developer \\
\hline 6. & Get some time off \\
\hline 7. & Submit the app to the iTunes Store \\
\hline 8. & Adapt, market and survive \\
\hline
\end{tabular}

This list and others like it give the impression that developing an app for a smartphone is quick and easy and all it takes is an idea and some time. This overly simplistic presentation may mislead potential entrepreneurs and does not provide much guidance to developers. Step 8 in particular may prove to be difficult. As stated by Walmsley [17] "the apps market seems to attract those who prefer to leap straight to the execution, missing out all those tiresome planning steps'" p. 18. The lists also fail to mention the required business acumen required to successfully market and operate a business. 
This paper will examine the attractiveness of the smartphone application industry as an avenue for entrepreneurship. Factors related to success/failure in entrepreneurial endeavors will be used to evaluate the attractiveness of the app market.

\section{Smartphones and Apps}

A smartphone is a mobile phone device that offers computing ability that allows users of smartphones to access the internet as well as run software based applications. First introduced in the mid 2000's, ownership and usage of smartphones has grown rapidly [10]. As the popularity of smartphones has soared, so has the demand for apps. The number of smartphones is driving what Manjoo [14] termed "app mania." This mania is further fueled by the manufacturers of operating systems collaborating with outside parties to develop apps that run on their system as a means to secure adoption of their operating system in the market place [1]. As in any situation where there is revenue potential, many people and companies are developing apps thus competition is intense. The range of apps runs a gambit from games to highly specialized software for proprietary applications. Pricing in the app market also runs the gambit from free to subscription based to high priced.

\section{FACTORS THAT AFFECT THE ATTRACTIVENESS OF AN ENTREPRENEURIAL VENTURE}

There are a wide variety of factors that influence the success/failure of an entrepreneurial venture [16]. This analysis will focus on competitive intensity, market factors, opportunity factors, barriers to entry, required investment, revenue stream and sustainable competitive advantage.

\section{Competitive Intensity}

Competitive intensity refers to the degree to which firms or entities in a market are in competition with each other $[1,15]$. The app market can be characterized as a large number of individuals and a moderate number of firms striving to create apps for a small number of outlets to service a large number of users. There are literally hundreds of thousands of developers registered with the various app development sites. Also in the mix are larger firms like Microsoft that are developing applications. Within the app market there are a number of market segments targeted toward specific types of purpose and specific target markets. Common market segments include games, utilities and business related software.

The David vs. Goliath competitive structure creates interesting challenges for small scale developers trying to develop and maintain a sustainable competitive advantage. This is further hampered by the number of operating systems - a successful app on one operating system can be copied by another developer for use on a different operating system. In the app market it is difficult to establish and maintain a sustainable competitive advantage. A premium app that is successful can be imitated by a free app funded by advertising that perform the same functions as a premium app further eroding profit potential for the app developer.

\section{Market Size/Growth}

The market for apps is expected to grow both in terms of downloads and in revenue. It is expected that by 2014 the number of apps downloaded will reach 6.67 billion downloads per year [7]. Financially, the app market revenue is expected to grow to $\$ 15.6$ billion by 2013 [10]. Competitive intensity often creates the need for high level collaboration between entities in order to survive and grow [1]. In the smartphone market there is often collaboration between the firms that produce operating systems and app developers. To the makers of smartphone operating systems, apps represent an almost symbiotic relationship. The number, type and usefulness of apps available for a particular operating system provide a means for product differentiation and hence an opportunity to increase market share and profitability. 
Volume XII, No. 1, pp. 313-317, 2011

\section{Barriers to Entry}

Barriers to entry into the market has long been a major consideration for entrepreneurial endeavors. Entry barriers can take many forms [13] and can affect the market place in many ways. While it may appear that the app market does not have any barriers to entry, there are significant decisions that must be addressed. The selection of an operating system to base the app on is crucial $[4,6,12]$. Many would be app developers, due to resource limitations, must focus on a single operating system. In contrast larger firms have the resources to develop multiple versions of their application software giving them substantial advantages in the market place. The decision of which operating system is further complicated by the ever shifting tides of market share. One must also consider the number of smartphones that use the given system and the demographic profile of the users. Also to be considered is coverage area. Cell phone providers, in particular smartphone providers are notorious for areas of limited service.

A second barrier to entry is gaining distribution. Often apps are sold by the companies that make the operating system. Of the app distributers the most well known Apple's App Store. In order to create sales or downloads, app developers must gain placement in the distributors system. Quite often this involves a number of hurdles and many issues in legality and more recently, security. Again, the internet provides "guidance" on areas that smartphone app developers need to address. Table 2 [8] presents a list of legal issues found on the internet that must be considered.

Table 2

Legal Issues for Application Software [8]

\begin{tabular}{|ll|}
\hline - & Protecting ideas in early stages of pitching to potential clients. \\
\hline - & Application developer agreements and API Terms of Use (TOUs). \\
\hline - & $\begin{array}{l}\text { Platform question: As a developer, how do you think about development based on different platform } \\
\text { (e.g. Android or iOS or Blackberry) or a specific API? }\end{array}$ \\
\hline - & Copyright and "open source” issues, GPL, libraries, use of third-party code. \\
\hline - & Ownership and Rights Issues \\
\hline - & Privacy and uses of personal information (PI) \\
\hline
\end{tabular}

Given that the makers of operating systems and smartphones have a vested interest in the number, quality and desirability of apps that will run on their products, each app store or download source has resources that app developers can use to develop and offer an app. The time frame from app development to deployment can vary widely. In some cases, years might be the time frame or in the case of GetJar [2], some apps are approved for listing in as little as one day. Recent events involving type, level and specificity of information captured by smartphone apps have raised concerns about data security. There has been talk of the smartphone industry establishing some form of self-regulation [5] which, among other things, likely delay the time it takes between app development and app deployment.

\section{Required Investment}

For many would-be entrepreneurs, the app market would not seem to require a large level of investment. To the naïve, it would appear that all that one would need is a relatively small investment in software, knowledge of programming, a computer and a place to work. Things however are not quite that simple. Many issues must be addressed, all of which will require monetary resources. First of course is protecting the product name and functions. This will require a copyright—contrary to popular belief, the "poor-man's" copyright (a detailed letter mailed to oneself to achieve a post-mark date to establish date created) rarely holds up in court. Second are the expenses associated with distribution and promoting the app. In order to purchase an app, people must be aware of the app. 
Volume XII, No. 1, pp. 313-317, 2011

\section{Revenue Stream}

A major consideration regarding developing and marketing apps is how is money made? While it is true that the app market is large and growing, a key question is where the money that apps generate comes from. Currently there are three paths. Path 1 is based upon the sale of the app. The average price of apps increased by 43 percent last year currently, the average app costs $\$ 2.85$ [9]. A concern with the app for pay model is, depending upon the rate of adoption and competitive reactions, apps may not have a long period in which to recoup initial investments and bring positive return on investment. Brodsky [3] suggests the many apps are merely "pop” technology—here today and gone tomorrow and as such offer a limited revenue stream. For apps that are successful and have long range potential, competitors are encouraged to produce alternate versions that provide the same or similar functions in order to share in the profit potential. A second path to revenue generation is through advertising revenue. In this scenario, the app is basically given away or offered at a very low price and users of the app are exposed to advertising messages. In turn, the app developer is paid from advertising revenue. Many app developers have opted to by-pass the app for sale market in favor of apps sponsored by advertisers [14]. Although sales of interactive advertising on the web is expected to remain flat the sales of interactive advertising on mobile is expected to grow [14]. The viability of this path is dependent upon the number of people who will use the app as well as whom the people using the app are. If the users of the app are in the right demographic profile or represent a good match between a producer's product/service and their target market, this path can lead to higher profitability as well as the funding necessary to maintain/expand the business. The third avenue is subscription based pricing. This is implemented when users pay a periodic fee to use a particular app. While this path offers a continuous stream of revenue, consumers may look for cheaper or free alternatives. Subscription based pricing is also subject to competitive encroachment from free or advertising sponsored copy apps.

\section{CONCLUSION}

The development and marketing of smartphone apps does indeed provide entrepreneurial opportunities. These opportunities however, like most other entrepreneurial opportunities require a sound business plan and considerable work. Far more than a little programming goes into making an app a success. Careful planning must be undertaken to identify opportunities and develop products that offer sustainable competitive advantages. Business plans must be developed to establish, grow and defend market share.

\section{REFERENCES}

1. Ang, Siah Hwee (2008), "Competitive Intensity and Collaboration: Impact on Firm Growth Across Technological Environments," Strategic Management Journal, 29, 10, p1057-1075.

2. Ankeny, Jason (2010) “The App Store That's Never Closed,” Entrepreneur, Vol. 38, 2, p22-27.

3. Brodsky, Art (2010), "Pop Technology Is In Peril," Multichannel News, Vol. 31 Issue 22, p25.

4. Hamm, Steve "Smartphone Roulette," Business Week, June 22, 2009, p.28.

5. http://www.businessreport.com/news/2011/may/ 11/industry-weighs-policing-mobile-tchn1/

6. http://communities-dominate.blogs.com/brands/2010/07/understanding-smartphone-market-share-battle-not-forphones-is-for-platform.html

7. http://www.frost.com/prod/servlet/press-release.pag?docid=176853195

8. http://mirskylegal.com/2011/05/podcast-9-app-development-legal-issues-open-source-copyright-api-terms-ofuse-and-more/

9. http://www.mobileburn.com/news.jsp?Id=8999

10. http://www.research2guidance.com/smartphone-application-market-to-reach-us15-65-billion-in-2013/

11. http://www.squidoo.com/iphone- application- developer

12. http://www.zdnet.com/blog/btl/smartphones-a-look-at-the-app-count-market-share-disconnect/31121

13. Karakaya, Fahri and Roger A. Kerin (2007), "Impact of Product Life Cycle Stages on Barriers to Entry," Journal of Strategic Marketing, 15 (September), p269-280.

14. Manjoo, Farhad (2009), "APP MANIA," Fast Company, Issue 135, p72-79. 


\section{Issues in Information Systems}

Volume XII, No. 1, pp. 313-317, 2011

15. O'Cass, Aron, Jay Weerawardena (2010), "The Effects of Perceived Industry Competitive Intensity and Marketing-Related Capabilities: Drivers of Superior Brand Performance," Industrial Marketing Management, 39, 4, p571-581.

16. Song, Michael, Ksenia Podoynitsyna, Hans van der Bij and Johannes I. M. Halman (2008), "Success Factors in New Ventures: A Meta-analysis,” Journal of Product Innovation Management, 25, p7-27.

17. Walmsley, Andrew (2010), "The Application of Sense," Marketing, February 17, 2010 p. 18. 